\title{
Race, Ethnicity, and Alphabetically Ordered Ballots
}

\author{
Barry Clayton Edwards
}

\begin{abstract}
A number of scholars have recently argued that ballot order effects give certain candidates an unfair advantage in elections and have urged states to randomize or rotate the order of candidate names to make elections more rational and fair. This article suggests that advocates of reform have been too quick to concede that static ordering methods are nondiscriminatory. One common method of ballot ordering, arranging candidates in alphabetical order by their last names, disadvantages specific minority populations by pushing their candidates down the ballot. To substantiate this argument, I engineer two computer simulation experiments which show a significant link between ballot position and racial/ethnic status under alphabetic ordering laws. Asian Americans and Pacific Islanders are particularly burdened by these laws. Because courts apply a higher level of scrutiny to election laws that infringe fundamental voting rights than laws that merely regulate elections, the discriminatory impact of alphabetic ordering rules significantly bolsters the case to rotate or randomize ballot order.
\end{abstract}

A NUMBER OF SCHOLARS have recently argued that ballot order effects give certain candidates an unfair advantage in elections and have urged states to randomize or rotate the order of candidate names to make elections more rational and fair (e.g., Beazley, 2013; L. Miller, 2010). Courts have been reluctant to entertain Equal Protection challenges to ballot ordering laws and scholars tend to emphasize other arguments. This article suggests that advocates of reform have been too quick to concede that static ordering methods are nondiscriminatory. One common method of ballot ordering, arranging candidates in alphabetical order by their last names, pushes specific minority populations own the ballot. Because courts apply a higher level of scrutiny to election procedures that discriminate against a racial or ethnic minority group, evidence of discriminatory effect, to date neglected in the literature, significantly bolsters the case to rotate or randomize ballot order. ${ }^{1}$

While no state opted to alphabetically order its ballots to intentionally discriminate against a partic-

Dr. Barry Clayton Edwards is in the Department of Political Science at the University of Georgia in Athens, GA. ular minority group, this method of ordering ballots may have the unintended consequence of limiting particular minority groups' ability to participate in the political process. In particular, alphabetic ordering puts Asian Americans and Pacific Islanders (API) at a disadvantage because API surnames generally appear later in alphabetical order than do the names of other races and ethnicities. In this article, I discuss the legal status of alphabetically ordered ballots, offer a statistical analysis of the effect of alphabetic ordering on Asian American candidates, and discuss the implication of this research. I conclude that courts should strictly scrutinize laws that require alphabetically ordered ballots and find them unconstitutional.

\footnotetext{
${ }^{1}$ I use the terms "race and ethnicity" here because "Hispanic" is an ethnic, rather than racial classification, comparing Hispanics as a group to racial groups is problematic (Michelson, 2010; Schildkraut, 2012). Whether shared ethnicity outweighs potentially cross-cutting differences among Latino voters is an important question that goes beyond the scope of this work. The Latino/Hispanic category encompasses a number of nations of origin so the findings reported here may obscure variability within the Hispanic population.
} 


\section{THE LEGAL STATUS OF ALPHABETICALLY ORDERED BALLOTS}

Whether ballot order gives a certain candidate, particular the first-listed candidate an unfair advantage in an election is of long-standing interest to political scientists and legal scholars (Bain and Hecock, 1957; Brooks, 1921; Mackerras, 1968; Mueller, 1969, 1970; White, 1950; Wilson, 1910). The primary cause for concern has been that the first-listed candidate will receive a windfall of carelessly cast votes. Although there is substantial dispute over the nature and magnitude of ballot order effects, the vast majority of applied works find that some small percentage of votes is determined by ballot position and this windfall largely goes to the first-listed candidate (Bain and Hecock, 1957; Brockington, 2003; Brook and Upton, 1974; Ho and Imai, 2008; Koppell and Steen, 2004; Meredith and Salant, 2013; J. M. Miller and Krosnick, 1998; Mueller, 1969, 1970; Volcansek, 1981; White, 1950). Political scientists explain ballot order effects in terms of voter behavior. When voters do not strongly identify with a party or the ballot lacks party identifiers (i.e., in primary or nonpartisan elections), a primacy effect leads voters to select the first candidate against whom they have no specific objection (Krosnick, 1991; J. M. Miller and Krosnick, 1998). ${ }^{2}$ These applied works are supported by controlled experimental analysis (Abakoumkin, 2011; Johnson and Miles, 2011) and well as Internet marketing research (Introna and Nissenbaum, 2000; Murphy, Hofacker, and Mizerski, 2006; Pan et al., 2007). This article does not offer any additional proof that being listed at the top of a ballot helps a candidate, but suggests that there is ample reason to believe that candidates benefit from being listed first on a ballot. ${ }^{3}$

Recently, Professor Mary Beth Beazley (2013) offered a compelling case for rotating the order of candidate names to minimize effects of voting errors and prevent post-election litigation. According to Beazley, the problem is not limited to careless voting, but rather extends to votes miscast for candidates in proximity to intended selections and votes miscast because of ballot design flaws. These problems are disturbing because the outcomes of many elections are within the margins of votes likely contaminated by ballot order. These are persuasive arguments, but I believe there may be a stronger legal argument against alphabetically ordered ballots.
Table 1. States that Alphabetically Order Primary or General Election Ballots

\begin{tabular}{lc}
\hline State & Year enacted \\
\hline Alabama & 1923 \\
Delaware & 1915 \\
Florida & 1971 \\
Georgia & 1933 \\
Hawaii & 1960 \\
Indiana & $1945-1991$ \\
Louisiana & 1952 \\
Maine & 1954 \\
Maryland & 1957 \\
Massachusetts (ia) & 1894 \\
Nevada & 1891 \\
New Hampshire (ps) & $1979-2006$ \\
Rhode Island & $1947-1994$ \\
South Carolina & 1996 \\
Tennessee & 1972 \\
Vermont & 1912 \\
\hline
\end{tabular}

Notes: (ia), alphabetical after incumbent; (ps), state legislative elections only.

Using a variety of primary and secondary sources, I have identified thirteen states in Table 1 that currently order primary and/or general election ballots alphabetically along with three states that have done so fairly recently (Krosnick, Miller and Tichy 2004; Miller 2010; Scott 1972; Gillie 1989). ${ }^{4}$ Generally, alphabetic ordering is used because it seems fair and is relatively easy to implement. ${ }^{5}$

Although alphabetic ordering may confer a windfall of careless votes on candidates with early

${ }^{2}$ In nonpartisan elections, where voters lack partisan cues to distinguish one candidate from another, voters' beliefs about a candidate's race or ethnicity based on his or her name may become significant, possibly offsetting (or compounding) name order effects.

${ }^{3}$ See Kautenburger v. Jackson, 333 P.2d 293, 295 (Ariz. 1958) (advantage to first-listed candidate is "a commonly known and accepted fact").

${ }^{4}$ Alabama's enactment year was determined by consulting its legislative history. Section 535 of the 1907 Code did not require primary voters to prepare ballots at the voting place. The Alabama Code of 1923, Section 623, however, required the names of candidates for each office to be printed in alphabetical order by surnames. In 1991, Indiana modified its ballot ordering rule, Indiana Stat. 3-10-1-18, to determine the order of candidates by lottery in counties with more than 400,000 but less than 700,000 residents. The Supreme Court of New Hampshire in Akins v. Secretary of State, 904 A.2d 702, 707 (N.H. 2006) declared the state's alphabetic ordering scheme unconstitutional. I did not attempt to categorize states based on distinct ballot ordering rules for local elections, run-offs, odd-year elections, or special elections.

${ }^{5}$ Other states arrange candidates by votes received in a prior contest, by the order that candidates filed for election, or in columns by party (L. Miller, 2010). 
alphabet surnames and contaminate the outcomes of some elections, this practice generally withstands legal challenges. The case of Schaefer $v$. Lamone, 2006 U.S. Dist. LEXIS 96855 (D. Md. 2006), is representative of the consensus legal view on alphabetically ordered ballots. ${ }^{6}$

Mike Schaefer was one of eighteen Democrats competing in a primary election to succeed Maryland Democrat Paul Sarbanes in the U.S. Senate. Because Maryland law requires alphabetically ordered ballots, Schaefer was the fourteenth listed candidate. Rep. Benjamin Cardin, the first-listed candidate, won the primary election and subsequent general election to the Senate. ${ }^{7}$ Schaefer challenged the constitutionality of Maryland's election law in federal court. First, Schaefer argued that Maryland's ballot order law violated his Equal Protection rights. Second, he maintained that the law infringed the fundamental right to vote, a liberty interest guaranteed by the due process clauses of the U.S. Constitution.

With respect to Schaefer's claim that alphabetically ordering ballots violates the Equal Protection rights of people with late-alphabet surnames, the court held that states may treat this class of people differently because alphabetic ordering is not a suspect classification. "He has not predicated a suspect class," the court held. "A suspect class is one that burdens people based on race, religion, national origin, ancestry, alienage, gender, or illegitimacy.... None of these classifications is implicated in Schaefer's suit" Id., at *5.

Under prevailing Equal Protection analysis, the district court's analysis of alphabetic ordering rules is likely correct. People with late alphabet surnames are not a protected class per se and states did not adopt these election laws to intentionally discriminate against candidates of a particular race or ethnicity. In Washington v. Davis, 426 U.S. 229, 96 S.Ct. 2040 (U.S. 1976), according to Yoshino (2010), the Supreme Court determined that "facially neutral state action would draw only ordinary rational basis review so long as it was not enacted with discriminatory intent....If legislators have the wit-which they generally do-to avoid words like 'race' or the name of a particular racial group in the text of their legislation, the courts will generally apply ordinary rational basis review. This tendency is true even if the state action has an egregiously negative impact on a protected group." See also City of Mobile v. Bolden, 446 U.S. 55, 100 S.Ct. 1490 (multi-member districts do not violate Fourteenth or Fifteenth Amendments absent intentional discrimination). ${ }^{8}$ Following this line of reasoning, alphabetically ordering ballots does not violate the Equal Protection Clause, even if the practice inadvertently harms a protected class.

The district court also rejected Schaefer's claim that Maryland's practice of alphabetically ordering ballots violated the fundamental right to vote. Courts strictly scrutinize laws that deprive citizens of liberties guaranteed by the due process clauses of the Fifth and Fourteenth Amendments. ${ }^{9}$ Because voting is a fundamental right, one that preserves other rights in a democratic society, courts may apply strict scrutiny to laws that affect voting rights, regardless of whether these laws make suspect classifications. See e.g., Kramer v. Union Free School District, 395 U.S. 621, 89 S.Ct. 1886 (1969) (strict scrutiny of voter residency requirements); Illinois State Board of Elections v. Social Workers Party

${ }^{6}$ See also Clough v. Guzzi, 416 F. Supp. 1057 (D. Mass 1976) (upholding Massachusetts's system of listing incumbents first, followed by other candidates in alphabetical order).

${ }^{7}$ It is interesting to note that Schaefer finished in fifth place, receiving only $1.32 \%$ of the votes, compared to Cardin's $43.67 \%$ share. It is safe to assume that the margin of Schaefer's defeat was greater than the percentage of votes affected by ballot order. However, the second place finisher, Rep. Kweisi Mfume, who was the ninth-listed candidate on the primary ballot, received $40.52 \%$ of votes in the primary (Maryland State Board of Elections, 2006). Cardin's 3.15\% victory over Mfume may be within the margin of votes affected by ballot order.

${ }^{8}$ Although potential plaintiffs would be hard pressed to show a state intended to discriminate against minority voters by requiring alphabetically ordered ballots, it should be noted that the intent requirement in Equal Protection cases is subject to varying interpretations. According to Ortiz (1989, pp. 1127-1128), the intent requirement may take on a different meaning in the electoral context: "the voting cases appear to require only a showing of disparate impact plus a showing that the jurisdiction has engaged in other types of discrimination in the past."

${ }^{9}$ As a matter of constitutional law, courts strictly scrutinize laws that make suspect classifications as well as laws that infringe on fundamental rights, such as the rights to marry, travel, and vote (Rich, 2011, pp. 430-434; Rotunda and Nowak, 2007, pp. 808821). The disparate impact of alphabetic ballot ordering does not justify strict scrutiny on the first basis (suspect classification), but may do so on the second (fundamental rights).

Commentators have criticized the Supreme Court's opinions in fundamental rights cases as confusing and inconsistent. It is not altogether whether fundamental rights are liberties protected by the due process clauses, an element of Equal Protection, or implied by the Constitution. In right to vote cases, Rotunda and Nowak (2007, p. 434) point out that there is a "potential circular pattern to this analysis" because the Court's standard compels a judge to decide the nature of the injury in order to determine which standard of review applies. Courts have "struggled" to identify the appropriate level of scrutiny in ballot order cases and remain divided, in part, due to "mixed signals" from the Supreme Court (L. Miller, 2010, pp. 395-396). 
et al., 440 U.S. 173, 99 S.Ct. 983 (1979) (strict scrutiny of candidate qualifying signatures standards). The right to vote does not merely allow voters and candidates to participate in the electoral process, but also guarantees the right to participate on equal terms. ${ }^{10}$ As Chief Justice Warren stated in Reynolds v. Sims, 377 U.SS. 533, 555, 84 S. Ct. 1362, 1378 (1964), "[The] right of suffrage can be denied by a debasement or dilution of the weight of a citizen's vote just as effectively as by wholly prohibiting the free exercise of the franchise."11

However, not all election laws implicate the right to vote. Ballot ordering rules do not prevent anyone from registering to vote, running for elected office, or voting in any election. How do we distinguish between laws that merely regulate elections and those which implicate the right to vote? When a case involves fundamental voting rights, a court should first consider the "character and magnitude of the asserted injury," Anderson v. Celebrezze, 460 U.SS. 780, 103 S.Ct. 1564 (1983). "[W]hen a state election law imposes only reasonable, nondiscriminatory restrictions upon the First and Fourteenth Amendment rights of voters, the State's important regulatory interests are generally sufficient to justify the restrictions," Burdick v. Takushi, 504 U.SS. 428, 112 S. Ct. 2059 (1992). Not every limitation or incidental burden on voting warrants strict scrutiny. Laws that regulate the time and place for voting are generally considered permissible regulations that allow states to conduct orderly elections.

Applying these fundamental rights decisions in Schaefer's case, the district court found that Maryland's alphabetic ordering rule was reasonable, nondiscriminatory, and served the State's legitimate interest in conducting orderly elections. Indeed, most courts that have considered whether ballot ordering rules implicate the fundamental right to vote have concluded that ballot ordering rules are mere regulations and justified by a state's interest in conducting orderly elections. The assumption that alphabetically ordering ballots is race-neutral has profound implications for how these laws should be reviewed. If the court had held that Maryland's ballot ordering rule had a discriminatory impact or imposed an unreasonable burden on voting, it should have subjected the rule to strict scrutiny and would likely have found the State's administrative convenience insufficient.

Although the opinion in Schaefer $v$. Lamone may represent the consensus view on the legality of alphabetically ordering ballots, courts in Arizona, California, and New Hampshire have held that this method of ordering ballots is unconstitutional. See Kautenburger v. Jackson, 333 P.2d 293 (Ariz. 1958) (based on state constitution); Gould v. Grubb, 536 P.2d 1337 (Cal. 1975) (fundamental rights analysis); Akins v. Secretary of State, 904 A.2d 702 (N.H. 2006) (based on state constitution). Nevertheless, alphabetical ordering remains the rule in at least thirteen states (see Table 1, above).

Scholars and courts have assumed, like the Maryland District Court, that alphabetically ordering candidates is a neutral method that does not have a discriminatory impact on any particular race or ethnicity. This assumption is incorrect. The court's analysis of the fundamental rights claim is wrong and this line of precedent should be overruled. The last names of different racial and ethnic groups are not similarly distributed alphabetically. Names are passed along from one generation to the next and, therefore, ballot ordering methods that disadvantage one group will tend to keep that group at a disadvantage from one generation to the next. Names are inherited conditions that characterize groups in the population. The mistaken assumption that alphabetic ordering is nondiscriminatory has lead courts to apply a lower level of scrutiny to these laws than is actually justified.

If alphabetic ordering inhibits fundamental voting rights by tending to disadvantage a particular race or ethnicity, courts should apply strict scrutiny to these laws. ${ }^{12}$ Under strict scrutiny analysis, a

\footnotetext{
${ }^{10}$ In City of Mobile v. Bolden, 446 U.S. at 75-80, 100 S.Ct. at 1504-1506, the Court recognized the fundamental right to participate in elections on an equal basis, but held that its infringement was not proven by lack of African American representation in Mobile's multi-member districts.

${ }^{11}$ The Court reiterated this point more recently in Bush et al. v. Gore et al., 531 U.SS. 98, 104-105, 121 S.Ct. 525, 530 (2000): "Having once granted the right to vote on equal terms, the State may not, by later arbitrary and disparate treatment, value one person's vote over that of another."

${ }^{12}$ It is not essential to this argument to demonstrate that alphabetic ordering has a discriminatory impact on minority voters as well as minority candidates. Both candidates and voters possess fundamental rights to participate in the political process on a level playing field and their rights are necessarily related. As the Supreme Court recognized in Bullock v. Carter, 405 U.SS. 134, 143, 92 S.Ct. 849, 856, "laws that affect candidates always have at least some theoretical, correlative effect on voters." The fact that minority voters tend to support minority candidates (Edwards, 2013) strengthens the central argument here; alphabetically ordering ballots tends to disadvantage both the candidates and voters of particular races and ethnicities.
} 
court would consider whether the state has a compelling interest in alphabetically ordering ballots, whether these rules are narrowly tailored to advance the state's interest, and whether there are less burdensome means of achieving the same ends. In addition to this constitutional argument, the Voting Rights Act may also offer disadvantaged groups a remedy. In the next section, I present evidence of discriminatory effect which makes these laws legally suspect.

\section{TESTING THE ASSUMPTION THAT ALPHABETICALLY ORDERING BALLOTS IS NON-DISCRIMINATORY}

In this section, I test whether alphabetic ordering tends to put one or more racial or ethnic groups in disadvantageous ballot positions. I assess the effect of alphabetic ordering on different racial and ethnic groups by engineering two computer simulation experiments using data on surnames from the U.S. Census Bureau.

The first experiment estimates the probability a candidate of a given race or ethnicity would be listed first in a two-person race against a white candidate. The second experiment estimates the probabilities of these candidates being listed in ballot positions one though five against four other candidates with names randomly drawn from the general population. The first experiment is intended to resemble a general election; the second experiment, a contested primary election (or a wide open general election). ${ }^{13}$

As part of the 2000 Census, the largest peacetime mobilization project in U.S. history (Hillygus, Nie, Prewitt, and Pals 2006, Chapter 2), the Census Bureau published a report on the 151,671 surnames that occur more than 100 times in the U.S. population (Word, Coleman, Nunziata and Kominski 2003). The surnames in this dataset account for $89.8 \%$ of U.S. population. ${ }^{14}$ In addition to reporting the frequency with which certain names appear in the U.S. population, the Census Bureau also reported the extent to which those with each name were African American, API, American Indian and Alaska Native (AIAN), Latino, or white. ${ }^{15}$ By multiplying the frequency of each name in the general population by its demographic make-up, I am able to estimate the distribution of names within each subpopulation. This extensive dataset on the demographic composition of names provides us an opportunity to assess the relationship between alphabetic order and protected classes of the population.

In Figure 1, I plot the alphabetic distributions of racial and ethnic subpopulations of surnames. This figure shows what proportions of different subpopulations have last names starting with each letter of the alphabet. The figure bears out that these racial and ethnic subpopulations are distributed very differently with respect to order of names in the alphabet. For example, only $6.8 \%$ of the API population has last names beginning with "A" or "B" while the comparable figure is $13.4 \%$ for the African American population, $14.0 \%$ for the AIAN population, $10.9 \%$ for the Hispanic population, and $12.7 \%$ for whites. In contrast, $5.8 \%$ of the API population has last name beginning with "X," "Y," or "Z"; comparable figures are $0.6 \%, 1.6 \%, 1.2 \%$, and $1.0 \%$ for the African American, AIAN, Hispanic, and white populations.

Although this figure offers some initial descriptive evidence of the relationship between race/ethnicity and alphabetic order, it may be the case that the differences among subpopulations cancel each other out over the course of many elections. For example, it is possible that the higher proportion of Hispanics with names beginning with "A" are balanced out by the higher proportion with names starting with "V," negating any net advantages or disadvantages.

\footnotetext{
${ }^{13}$ Carsey et al.'s (2007) dataset on State Legislative Election Returns, indicates that 54\% of general elections from 19672003 were two-candidate races; $20 \%$ involved more than two candidates; $26 \%$, only one candidate. Twenty-two percent of all major party primary elections in this dataset involved more than two candidates; $33 \%$ of major party primary elections without an incumbent had more than two candidates participate. We might expect congressional elections to attract even more candidates. Meredith and Salant's (2013) study of California city council and school board elections suggests that many general elections at the local level also feature more than two candidates.

${ }^{14}$ I assume that the extremely rare surnames excluded from the Census Bureau data are evenly distributed among the known surnames. Extremely name surnames (less than 100 with surname in population) account for only $10.2 \%$ of the population. ${ }^{15}$ These categories are not ideal. In addition to the problems noted with respect to the Hispanic category, grouping Asian Americans and Pacific Islanders together ignores significant political differences between and among these groups (Aoki and Takeda, 2008, pp. vi-vii). However, given that it cost about $\$ 5$ billion to conduct Census 2000, collecting better data on surnames is not a realistic possibility.
} 


\section{African American Population}

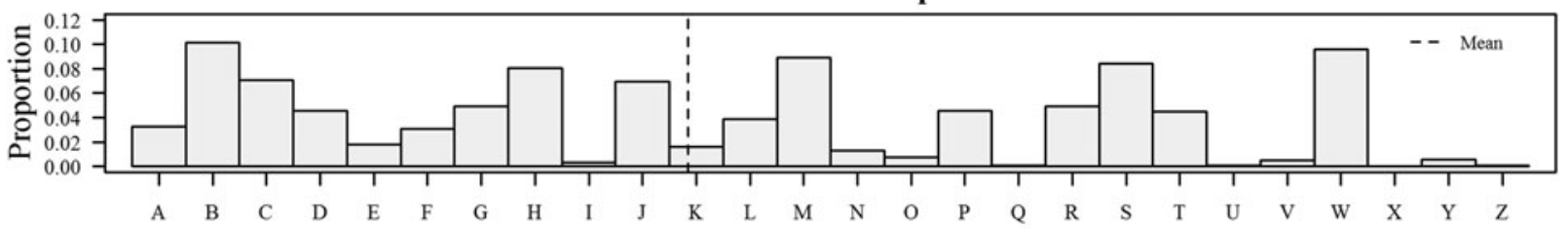

Asian American and Pacific Islander Population

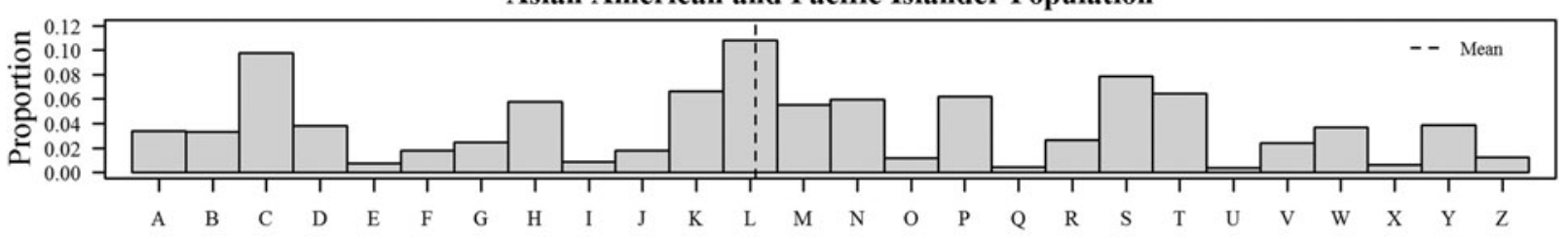

American Indian and Alaskan Native Population

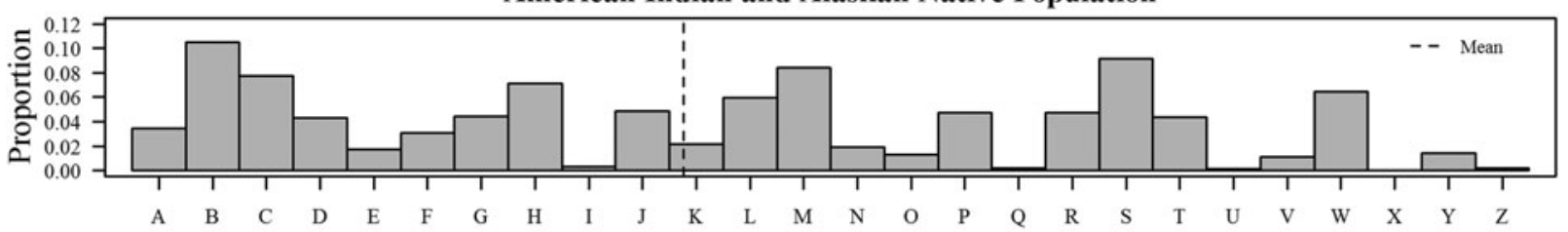

Hispanic Population

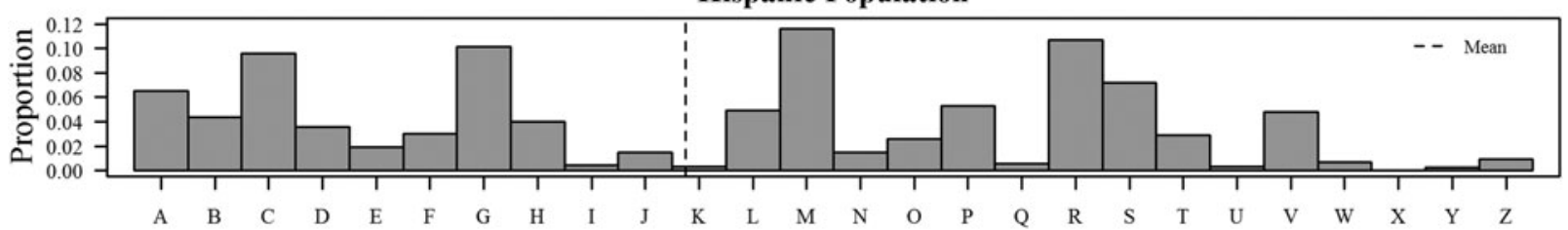

White Population

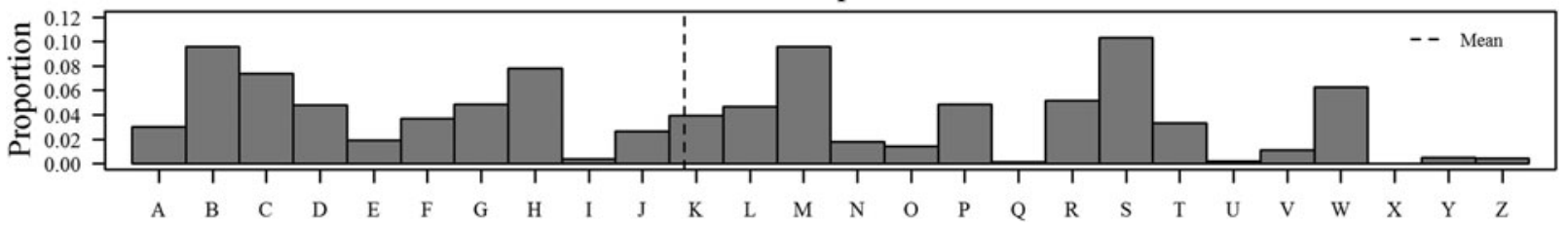

FIG. 1. Alphabetic distribution of surnames by race/ethnicity.

The differences among racial and ethnic groups evidence in Figure 1 do not simply cancel each other out. Alphabetic ordering tends to create distinct advantages and disadvantages for different subpopulations. How does alphabetic ordering affect the relative position of minority candidates against white candidates? To analyze this question, I engineer two computer simulation models. ${ }^{16}$ First, I draw 5,000 names from the various subpopulations with the probability of selecting each name equivalent to its frequency in the corresponding subpopulation. For each draw of names, I determine whether the minority or white candidate would be listed first on an alphabetically ordered ballot. ${ }^{17}$ If alphabetic ordering is not a factor in these contests, there should be a 0.5 probability that a minority candidate is listed first in a race against a white opponent. Therefore, I test whether estimated probabilities are significantly different than 0.5 . Table 2 , below, summarizes the results of this experiment.

This simulation of two-person, general elections reveals one significant difference among subpopulations. The probabilities that African American,

${ }^{16}$ I use computer simulation models rather than traditional statistical approaches because surnames do not follow well-defined distributions (i.e., names are not centered at " $\mathrm{M}$ " and "N" with decreasing frequencies at the beginning and ends of the alphabet). ${ }^{17}$ If two paired names were tied alphabetically, I ignored these pairings. There were twelve ties out of 25,000 name pairings. 
Table 2. Probability of Being Listed First Against White Opponent

\begin{tabular}{ll}
\hline Candidate racelethnicity & $\begin{array}{c}\text { Probability of being } \\
\text { listed first }\end{array}$ \\
\hline African American & 0.499 \\
Asian/Pacific Islander & $0.442^{* * *}$ \\
American Indian/Alaskan Native & 0.492 \\
Hispanic & 0.500 \\
White & 0.506 \\
\hline
\end{tabular}

$* * * p<0.001$ (two-tailed tests).

AIAN, Latino, or white candidates are listed first on an alphabetically ordered ballot against white candidates are not distinguishable from 0.5. However, the probability that an API candidate is listed before a white candidate on an alphabetically ordered ballot is only 0.4424 and this result is statistically significant at the $99.9 \%$ confidence level. ${ }^{18}$

What if, like Mike Schaefer, candidates compete in contests with more than two entrants? I evaluate group prospects in multi-candidate elections in a second simulation experiment. I again draw 5,000 names from the various subpopulations with the probability of selecting each name equivalent to its frequency in the corresponding subpopulation. ${ }^{19}$ In this simulation, I rank each name in alphabetical order against four randomly drawn names from the general population. This experiment is intended to simulate multi-candidate elections and test for positional advantages and disadvantages other than being first listed, such as being the last-listed candidate in a crowded field. If there were no relationship between race/ethnicity and ballot position under alphabetic order rules, the probability of appearing in the first, second, third, fourth, or fifth positions on the ballot would equal 0.2. Table 3 reports the results of this experiment.

Table 3 suggests that alphabetic order is not neutral with respect to different racial and ethnic groups. Interestingly, when competing against a field of four candidates picked at random from the general population, each subpopulation has exceptional probabilities of appearing in at least one of the five ballot positions. African American and AIAN candidates are more likely to appear as the end of the ballot than are other candidates. Latino candidates are less likely to be listed in the second position; white candidates, the fourth position on the ballot. The results for API candidates are particularly striking. API candidates have only a $16.22 \%$ chance of being listed first and a
Table 3. Probable Ballot Position for Candidates in Five-Person Contest

\begin{tabular}{llllll}
\hline & \multicolumn{5}{c}{ Racelethnicity of candidate } \\
\cline { 2 - 6 } Position & $\begin{array}{c}\text { African } \\
\text { American }\end{array}$ & API & AIAN & Hispanic & White \\
\hline First & 0.200 & $0.162 * * *$ & 0.205 & 0.205 & 0.209 \\
Second & 0.196 & $0.171^{* * *}$ & 0.192 & $0.189 *$ & 0.198 \\
Third & $0.190^{*}$ & 0.201 & 0.195 & 0.207 & 0.195 \\
Fourth & 0.195 & $0.219^{* * *}$ & 0.194 & 0.204 & $0.189 *$ \\
Fifth & $0.219^{* * *}$ & $0.247^{* * *}$ & $0.215^{* *}$ & 0.195 & 0.209 \\
\hline$* p<0.05 * * * p<0.01 * * * *<<0.001$ & & &
\end{tabular}

$* p<0.05 ; * * p<0.01 ; * * * p<0.001$.

API, Asian American and Pacific Islander; AIAN, American Indian and Alaska Native.

$17.08 \%$ chance of being listed second on the ballot in a five-candidate contest. In contrast, the chances that an API candidate will be listed in the fourth and fifth positions are $21.92 \%$ and $24.72 \%$, respectively. In sum, alphabetic ordering is not a neutral practice with respect to any group and it puts API candidates and their supporters at a decided disadvantage.

The primary election simulation experiment reported in Table 3 is consistent with the general election experiment reported in Table 2, but adds to the prior analysis in two respects. First, the primary elections simulation shows that relatively small differences among the racial/ethnic compositions of surnames are magnified as the candidate field increases. Second, the positional advantages and disadvantages of different racial and ethnic subpopulations under alphabetic ordering rules are not monotonic. Some racial and ethnic groups appear to be less likely to appear in the middle of an alphabetic listing while the probabilities are higher than lower than expected at either the beginning or end of the list for other subpopulations.

\footnotetext{
${ }^{18}$ This means that if the null hypothesis were true (the probability of an API candidate being listed first is 0.5 ), the probability of observing 0.4424 of API candidates listed first in 5,000 observations is less than $0.1 \%$. We have $99.9 \%$ confidence that we have correctly rejected the null hypothesis.

${ }^{19}$ In the multi-candidate situation, the probability of being listed first is not the probability that a candidate is listed first (from Table 2) raised to a power equal to the number of candidates because probability a given name comes before another in alphabetical order is not independent of the probability the name comes before another randomly selected name. If a candidate is listed first against one opponent (because the candidate has an early alphabet last name, like Rep. Cardin in the Schaefer $v$. Lamone case) the chances are relatively high he or she will be listed first against other opponents.
} 
How would these differences affect candidates' likely vote shares? The percentage of votes swayed by ballot order depends on the salience of the election and whether partisan cues are available on the ballot. Most research suggests that ballot order has minimal effect in high-profile general elections (Ho and Imai, 2008), but increases the vote share of the first-listed candidate by $2-5 \%$ in down-ballot races for state and local offices as well as primary and nonpartisan elections (Brockington, 2003; Koppell and Steen, 2004; Krosnick, Miller, and Tichy, 2004). In competitive elections, the margin of victory is frequently less than share of votes likely influenced by ballot order. Meredith and Salant (2013, p. 177) estimate that first-listed candidates are $4-5 \%$ more likely to win office (with greater advantages in elections with more candidates). The expected disadvantage to Asian American candidates in states that alphabetically order ballots is relatively small in absolute terms; however, as I discuss in the next section, ballot ordering laws that put a specific minority population at a disadvantage in the electoral process are legally suspect. $^{20}$

\section{IMPLICATIONS OF RESEARCH FOR LEGAL ANALYSIS OF ALPHABETIC ORDERING LAWS}

The primary purpose of this article is to challenge the prevailing assumption that alphabetically ordering ballots is a neutral method of administering elections. State laws that dictate alphabetically ordered ballots systematically disadvantage particular minority candidates and their supporters. This method of ordering ballots falls particularly hard on Asian Americans and Pacific Islanders. The surnames of this subpopulation are skewed to the latealphabet compared to those of other groups. States that alphabetize ballots, therefore, tend to push API candidates down the ballot, putting their supporters at a significant disadvantage. ${ }^{21}$ By denying specific populations equal opportunities to complete in elections, this ballot ordering method violates fundamental voting rights. Although alphabetically ordering ballots does not prevent API candidates and votes from participating in elections, this practice tends to undermine API candidates by debasing and diluting the weight of API votes.

Although people with late-alphabet surnames do not constitute a protected class for equal protection purposes, minority races and ethnicities, including Asian American and Pacific Islanders, are protected classes. These groups have suffered from prejudice and discrimination in the United States, limiting their opportunities to participate in American politics (see generally Aoki and Takeda, 2008, Chapter 1). "Early Asian Pacific immigrants in the nineteenth and twentieth centuries were disenfranchised and excluded from fully participating in key sectors of American life because of a plethora of discriminatory laws and policies" (Nakanishi and Lai, 2003, p. 3). These groups should not be further disadvantaged by the unintended consequences of ballot ordering rules. ${ }^{22}$

As discussed above, states are entitled to impose reasonable, nondiscriminatory regulations on voting and elections. A law that simply regulates elections need only have a rational basis. If the results reported here are correct, however, courts should strictly scrutinize state election laws that mandate alphabetically ordered ballots. When a law undermines a minority

\footnotetext{
${ }^{20}$ The expected disadvantage to an Asian American candidate reflects the joint probabilities of being assigned a disadvantageous ballot position and ballot position affecting the election outcome. If we assume an Asian American candidate has a $5 \%$ lower probability of a gaining $3 \%$ vote share or $5 \%$ greater probability of winning office, Asian American candidates can expect to lose $0.15 \%$ of votes and are $0.25 \%$ less likely to win office as a result of alphabetic ordering. Because the expected net effect on Asian American representation is relatively small, detecting differences in the proportions of Asian American electoral success under different ballot ordering rules would require very large samples. Although the expected impact on electoral success may be less than one percent, the degree of this type of invidious discrimination is not particularly relevant. See Harper v. Virginia Board of Elections, 383 U.SS. 663, 668, 86 S.Ct. 1079, 1082 (1966).

${ }^{21} \mathrm{~A}$ number of states that alphabetically order ballots have relatively small API populations. According to the U.S. Census Bureau's 2010 Demographic Profile Data, seven states listed in Table 1 have between 1-2\% API population (ME, AL, VT, $\mathrm{SC}, \mathrm{LA}, \mathrm{TN}$, and IN); five states have between 2-5\% API (NH, FL, RI, DE, GA). Massachusetts and Maryland have 5.3 and $5.6 \%$ API, respectively; Nevada, $7.8 \%$. Hawaii has an exceptionally large API population: $48.6 \%$ (38.6\% Asian and $10.0 \%$ Native Hawaiian or other Pacific Islander). The United States as a whole, is $4.9 \%$ API.

${ }^{22}$ Consider, for example, Eugene Yu's campaign to replace retiring Georgia Senator Saxby Chambliss in the U.S. Senate. $\mathrm{Yu}$, a Korean-American resident of Augusta, Georgia, will be the last candidate listed on Republican primary ballots because Georgia orders ballots alphabetically. Yu is a long shot by any account, but this race will likely be decided by a run-off election (Eidson, 2013). If Yu makes an impact in the primary, frontrunners may make an effort to appeal to his supporters to secure the majority of votes necessary for nomination (see Bullock and Johnson, 1992 on run-off campaign strategies).
} 
population's ability to participate in the electoral process, it is not a mere regulation, but rather infringes upon fundamental rights. Opting for rational basis review, courts have mistakenly assumed that these laws are nondiscriminatory. In a case like Schaefer $v$. Lamone, strict scrutiny analysis would have required Maryland to demonstrate a compelling state interest in alphabetically ordering ballots, show that its ballot ordering rule is narrowly tailored to meet this interest, and that less restrictive means are not available. Had the district court applied this standard, it probably would have found the Maryland statute unconstitutional. My research suggests this case was decided incorrectly and Maryland's law for ballot ordering violates the fundamental voting rights of protected classes of the population.

In addition to the constitutional argument against alphabetically ordering ballots, Asian Americans would appear to have a strong claim under the Voting Rights Act (VRA). ${ }^{23}$ Section 2 of the VRA creates a right of action against laws "used for the purpose or with the effect of denying or abridging the right of any citizen of the United States to vote on account of race or color[.]" 42 U.SS.C. $\S$ 1973a(b). Section 2 applies nationwide and allows plaintiffs to challenge existing laws. Since the 1980s, VRA litigation has focused on practices, procedures, or prerequisites to voting that diminish minorities' political influence (Tokaji, 2005). Prior claims that static ballot ordering laws illegally dilute votes have generally failed (L. Miller, 2010, p. 397). As discussed above, courts have assumed that there is no legally significant pattern to who gains and who loses votes when ballots are alphabetically ordered. The VRA does not protect candidates with late alphabet names, but would protect the voting rights of group that tends to have late alphabet names from having their voting diluted. Potential plaintiffs could also argue alphabetically ordering ballots violated Section 5 of the Act, but in light of the Court's recent decision to invalidate the historic coverage formula, it is not clear where Section 5 applies. $^{24}$

Although states have a significant interest in orderly elections, the case for alphabetically ordering ballots is limited. States conduct orderly elections using a variety of other ballot ordering methods. Moreover, states can administer elections without burdening or benefitting certain racial and ethnic groups at the expense of other groups. For example, states can assign ballot order by lottery or rotate the order of candidates among precincts. ${ }^{25}$ As voting technology advances (Alvarez and Hall, 2010), these alternative methods of ordering candidates are becoming less expensive and more reliable. A crude method like alphabetic ordering may yield marginal savings, but the benefit compared to other methods is not compelling. As Beazley (2013) points out, such arbitrary ballot ordering schemes invite voter error and are often subject to post-election litigation.

Proponents of existing rules may argue that the effect of ballot order is marginal and that the types of position advantages documented here are likely to even out over the course of many elections. These arguments contain seeds of truth but do not justify alphabetic ordering when fundamental rights are at issue. While it is true that the effect of ballot order is relatively small, perhaps on the order of $2-5 \%$, it probably decides who wins and loses some elections given margins of victory are frequently less than 2-5\%. Likewise, while API candidates and their supporters may pick up some of the windfall votes they lose by not being listed at the top of the ballot by being listed, more often than others, at the bottom of the ballot, this crude notion of fair play should not prevail when the ability of a protected class to participate in the political process is at issue.

\section{CONCLUSION}

The contemporary debate over ballot ordering laws and ballot reform measures has paid relatively little attention to the implications of ordering

\footnotetext{
${ }^{23}$ Like Mike Schaefer, a plaintiff challenging a state ballot ordering law could plead his or her claims in the alternative. Liberal pleading rules would allow a plaintiff to make both constitutional and statutory arguments against alphabetically order ballots.

${ }^{24}$ Section 5 prohibits any change to state voting laws "that has the purpose of or will have the effect of diminishing the ability of any citizens of the United States on account of race or color...to elect their preferred candidates of choice." 42 U.SS.C. $\S 1973$ c(b).

${ }^{25}$ Rotation and randomization are distinct solutions. Rotation essentially neutralizes the impact of static ballot ordering, while assigning order by lottery randomizes which candidates will feel the impact. Both practices would solve the discriminatory impact of alphabetically ordering ballots, but rotation better addresses the problem of carelessly cast votes deciding elections than does assigning order by lottery.
} 
methods for different racial and ethnic groups. At least one common method of organizing ballots, arranging candidates in alphabetical order by last name, is not neutral with respect to race and ethnicity. The surnames of different racial and ethnic groups are not similarly distributed with respect to alphabetic order. The evidence presented in this article suggests that alphabetic ordering does not treat any racial or ethnic subpopulation for which reliable demographic information is available in an entirely even-handed manner. This method of ballot order is particularly detrimental for Asian American and Pacific Islander candidates who are likely to appear further down an alphabetized ballot compared to other candidates. Alphabetically ordering ballots may seem like a fair and practical method of organizing ballots on first impression, but it has been a long-standing point of controversy and likely has a discriminatory effect. This article supports recent calls to reform ballot order laws by randomizing or rotating the order of candidate names (Beazley, 2013; L. Miller, 2010) and suggests a promising legal strategy against alphabetic ordering laws currently in place.

\section{REFERENCES}

Abakoumkin, G. (2011). Forming Choice Preferences the Easy Way: Order and Familiarity Effects in Elections. Journal of Applied Social Psychology, 41(11), 2689-2707.

Alvarez, R. M., and Hall, T. E. (2010). Electronic Elections: The Perils and Promises of Digital Democracy. Princeton, NJ: Princeton University Press.

Aoki, A., and Takeda, O. (2008). Asian American Politics. Cambridge, UK: Polity Press.

Bain, H. M., and Hecock, D. S. (1957). Ballot Position and Voter's Choice. Detroit, MI: Wayne State University Press.

Beazley, M. B. (2013). Ballot Design as Fail-Safe: An Ounce of Rotation Is Worth a Pound of Litigation. Election Law Journal, 12(1), 18-52.

Brockington, D. (2003). A Low Information Theory of Ballot Position Effect. Political Behavior, 25(1), 1-27.

Brook, D., and Upton, G. (1974). Biases in Local Government Elections Due to Position on the Ballot Paper. Applied Statistics, 23(3), 414-419.

Brooks, R. C. (1921). Voters' Vagaries: The Value of Position on a Ballot. National Municipal Review, 10(3), 161-165.

Bullock, C. S., and Johnson, L. K. (1992). Runoff Elections in the United States. Chapel Hill, NC: University of North Carolina Press.

Carsey, T. M., Berry, W. D., Niemi, R. G., Powell, L. W., and Snyder, J. M. (2007). State Legislative Election Returns, 1967-2003. Dataset available at <http://doi.org/10.3886/ ICPSR21480.v1 > .
Edwards, B. C. (2013). Formulating Voting Rights Act Remedies to Address Current Conditions. American Politics Research. doi: 10.1177/1532673X13499624.

Eidson, S. (2013, Dec. 4). Meet Eugene Yu: Born in South Korea, This Long-Time Augusta Resident is Battling against Career Politicians for the Seat of Retiring U.S. Senator Saxby Chambliss, Metrospirit. Retrieved from < http:// metrospirit.com/meet-eugene-yu $>$.

Ho, D. E., and Imai, K. (2008). Estimating Causal Effects of Ballot Order from a Randomized Natural Experiment The California Alphabet Lottery, 1978-2002. Public Opinion Quarterly, 72(2), 216-240.

Introna, L. D., and Nissenbaum, H. (2000). Shaping the Web: Why the Politics of Search Engines Matters. The Information Society, 16(3), 169-185.

Johnson, A. J., and Miles, C. (2011). Order Effects of Ballot Position without Information-Induced Confirmatory Bias. British Politics, 6(4), 479-490.

Koppell, J. G., and Steen, J. A. (2004). The Effects of Ballot Position on Election Outcomes. Journal of Politics, 66(1), 267-281.

Krosnick, J. A. (1991). Response Strategies for Coping with the Cognitive Demands of Attitude Measures in Surveys. Applied Cognitive Psychology, 5(3), 213-236.

Krosnick, J. A., Miller, J., and Tichy, M. (2004). An Unrecognized Need for Ballot Reform: The Effects of Candidate Name Order on Election Outcomes. In M. J. A. Crigler, and E. McCaffery (Ed.), Rethinking the Vote: The Politics and Prospects of American Election Reform. New York: Oxford University Press.

Mackerras, M. (1968). The "Donkey Vote." The Australian Quarterly, 40(4), 89-92.

Maryland State Board of Elections. (2006). Official 2006 Gubernatorial Primary Election results for U.S. Senator. from < http://www.elections.state.md.us/elections/2006/ results/primary/office_US_Senator.html >

Meredith, M., and Salant, Y. (2013). On the Causes and Consequences of Ballot Order Effects. Political Behavior, 35(1), 175-197.

Michelson, M. R. (2010). Majority-Latino Districts and Latino Political Power. Duke Journal of Constitutional Law and Public Policy, 5, 159-175.

Miller, J. M., and Krosnick, J. A. (1998). The Impact of Candidate Name Order on Election Outcomes. Public Opinion Quarterly, 62, 291-330.

Miller, L. (2010). Election by Lottery: Ballot Order, Equal Protection, and the Irrational Voter. New York University Journal of Legislation and Public Policy, 13, 373-405.

Mueller, J. E. (1969). Voting on the Propositions: Ballot Patterns and Historical Trends in California. American Political Science Review, 63(4), 1197-1212.

Mueller, J. E. (1970). Choosing Among 133 Candidates. Public Opinion Quarterly, 34(3), 395-402.

Murphy, J., Hofacker, C., and Mizerski, R. (2006). Primacy and Recency Effects on Clicking Behavior. Journal of Computer-Mediated Communication, 11(2), 522-535.

Nakanishi, D. T., and Lai, J. S. (2003). Asian American Politics: Law, Participation, and Policy. Oxford, UK: Rowman \& Littlefield. 
Ortiz, D. R. (1989). The Myth of Intent in Equal Protection. Stanford Law Review, 41(5), 1105-1151.

Pan, B., Hembrooke, H., Joachims, T., Lorigo, L., Gay, G., and Granka, L. (2007). In Google We Trust: Users' Decisions on Rank, Position, and Relevance. Journal of ComputerMediated Communication, 12(3), 801-823.

Rich, W. J. (2011). Modern Constitutional Law, Third Edition, Volume I. Eagan, MN: West.

Rotunda, R. D., and Nowak, J. E. (2007). Treatise on Constitutional Law: Substance and Procedure, Fourth Ed., Volume II. St. Paul, MN: Thomson West.

Schildkraut, D. J. (2012). Which Birds of a Feather Flock Together? Assessing Attitudes About Descriptive Representation Among Latinos and Asian Americans. American Politics Research, 41(4), 699-729.

Tokaji, D. P. (2005). New Vote Denial: Where Election Reform Meets the Voting Rights Act, The. South Carolina Law Review, 57, 689-734.
Volcansek, M. L. (1981). An Exploration of the Judicial Election Process. The Western Political Quarterly, 34, 572-577.

White, H. (1950). Voters Plump for First on List. National Municipal Review, 39(2), 110-111.

Wilson, W. (1910). Hide-and-Seek Politics. North American Review, 191(654), 585-601.

Yoshino, K. (2010). The New Equal Protection. Harvard Law Review, 124, 747-803.

Address correspondence to: Barry Clayton Edwards Department of Political Science University of Georgia 104 Baldwin Hall Athens, GA 30602

E-mail: bce@uga.edu 